\title{
Being unvaccinated and contact with measles cases as the risk factors of measles outbreak, North Sumatera, Indonesia
}

\author{
Frans Yosep Sitepu ${ }^{\mathrm{a}, *}$, Elpiani Depari ${ }^{\mathrm{b}}$, Mudatsir Mudatsir ${ }^{\mathrm{c}, \mathrm{d}, \mathrm{e}, * *}$, Harapan Harapan $^{\mathrm{c}, \mathrm{d}, \mathrm{e}, * * *}$ \\ ${ }^{\text {a }}$ Provincial Health Office, North Sumatera, Indonesia \\ ${ }^{\mathrm{b}}$ Grandmed Hospital, Deliserdang, North Sumatera, Indonesia

 \\ ${ }^{\mathrm{d}}$ Department of Microbiology, School of Medicine, Universitas Syiah Kuala, Banda Aceh, Indonesia \\ ${ }^{\text {e } T r o p i c a l ~ D i s e a s e ~ C e n t r e, ~ S c h o o l ~ o f ~ M e d i c i n e, ~ U n i v e r s i t a s ~ S y i a h ~ K u a l a, ~ B a n d a ~ A c e h, ~ I n d o n e s i a ~}$
}

A R T I C L E I N F O

\section{Keywords:}

Measles

Rubeola

Outbreak

Vaccination

Vaccine hesitancy

\begin{abstract}
A B S T R A C T
Background: Measles is a highly contagious and a vaccine-preventable disease. On 14 August 2015, a measles outbreak was reported in Langkat District, North Sumatra province of Indonesia. To investigate the risk factors of the outbreak and to recommend control measures, an epidemiological investigation was undertaken. Method: A 1:1 matched case-control study was conducted. All suspect and confirmed cases were recruited and included. Controls were healthy neighbors of cases, matched for age and gender. House-to-house search for cases was carried out. Structural interviews were conducted to solicit demographic data, clinical data, as well as the risk factors. A two-step logistic regression was employed to assess the potential risk factors associated with the infection.

Results: During 20 July to 25 September 2015, a total of 28 measles cases were identified with no death. All tested blood samples were positive for measles-specific IgM antibodies confirming the outbreak. All cases presented with fever and rash; cough (80\%), coryza (65\%), and conjunctivitis $(25 \%)$. The attack rate (AR) was $14.1 \%$ (age ranged between 1 and 14 years old), the highest AR (50.0\%) occurred among those aged 1-4 years. In multivariate model, those who have not received measless vaccication and those who had contact with a measles case had higher odds of having infection, with adjusted odds ratio (aOR): 2.31 (95\%CI: 1.22-4.27) and aOR: 1.15 (95\%CI: 1.12-3.70), respectively.

Conclusions: Being unvaccinated and having a contact history increased the risk of measles are two risk factors of measles infection. A mass measles immunization to the school children was undertaken and a strict measles surveillance and notification system were recommended to control the transmission in the future.
\end{abstract}

\section{Introduction}

Measles, caused by measles virus, is a highly contagious and a serious disease in particular in children. ${ }^{1-3}$ It is transmitted through droplets from nose, mouth or throat of an infected person with incubation period is approximately 10-14 days (range 7-23 days). ${ }^{2,4}$ Clinical manifestations including fever, malaise, cough, coryza, and conjunctivitis, followed by maculopapular rash. ${ }^{1,5,6}$ The rash develop from the upper face and neck and gradually spreading downward. ${ }^{1,2}$ Severe measles and complications are likely occur among young children with immune deficiency disorders, malnutrition, and vitamin A deficiency. ${ }^{7}$ Encephalitis is the most common cause of long-term sequelae among measles patients while pneumonia, croup, and encephalitis are the common causes of death. ${ }^{7}$

Indonesia is one of the countries with the highest incidence rate of measles $^{6,8}$ with more than 11,000 cases reported annually in which $12-39 \%$ are confirmed cases. ${ }^{9}$ Several measles outbreaks have been reported in Indonesia such as in Serdang Bedagai District, North Sumatera between December 2011 and January 2012 with 83 cases. ${ }^{10}$ In 2014 and 2015, measles outbreaks were also reported in Banjarmasin of South Kalimantan ${ }^{11}$ and Bantul of Yogyakarta, respectively. ${ }^{12,13}$ One of the biggest outbreaks occurred in East Java Province in 2016 where 3,765 cases were reported and this associated with low level of vaccination covarage. ${ }^{14,15}$ In the national scale, between 2010 and 2015, it

\footnotetext{
* Corresponding author. Provincial Health Office, North Sumatera, Indonesia.

${ }^{* *}$ Corresponding author. Department of Microbiology, School of Medicine, Syiah Kuala University, Banda Aceh, Indonesia.

*** Corresponding author. Medical Research Unit, School of Medicine, Syiah Kuala University, Banda Aceh, Indonesia.

E-mail addresses: franz_sitepu@yahoo.co.uk (F.Y. Sitepu), mudatsir@unsyiah.ac.id (M. Mudatsir), harapan@unsyiah.ac.id (H. Harapan).
} 
was estimated that 23,164 measles cases occurred in Indonesia. ${ }^{16,17}$ It is believed that the actual number is higher considering that many cases were unreported, in particular from private health centres where the completeness rate of the surveillance reports is low. ${ }^{18}$

Indonesian Ministry of Health (MoH) committed to achieve measles immunization coverage as high as $95 \%{ }^{16}$ in which it will give herd immunity and break the chain of transmission of the disease. ${ }^{18}$ Despite persistent efforts to reach the target have been conducted by government, the trend of measles immunization coverage tends to decrease. ${ }^{16,17,19}$ In 2017, there were 23 out of 34 provinces in Indonesia did not achieve the target of measles immunization coverage, including North Sumatera. ${ }^{16}$

On 14 August 2015, District Health Office of Langkat in North Sumatera province received a notification of suspected measles outbreak in Tanjung Pura Subdistrict. As a response, one day later, on 15 August, an epidemiological investigation was conducted by surveillance officers from District Health Office and Provincial Health Office to investigate the outbreak, identify the risk factors and to recommend the control measures.

\section{Methods}

\subsection{Study site}

Measles outbreak occurred in Pekubuan Village. It is located in Tanjung Pura Subdistrict, Langkat District, North Sumatera province with a total area of 5.82 square kilometers $\left(\mathrm{km}^{2}\right)$. In 2015 , the total population was 5,056 with population density of 869 people $/ \mathrm{km}^{2}$. The distance from the village to the capital of Tanjung Pura Subdistrict is $1.2 \mathrm{~km}$ and to the district capital is $19.2 \mathrm{~km}$. The village consists of 1,242 households, and as many as 215 households are pre-prosperous families. Majority of population are farmers. ${ }^{20}$

\subsection{Study setting}

An 1:1 matched case-control was conducted from 15 August to 25 September 2015. All suspect and confirmed measles cases were included. A suspected case defined as the resident with acute fever, rash, and one or more symptoms of cough, coryza, or conjunctivitis with onset from 20 July to 25 September 2015. A confirmed case was the suspected case with specific anti-measles IgM positive. One control for each case, a neighbor of the case who had no clinical sign and symptom of measles, was recruited in the study.

\subsection{Data collection procedure}

A house-to-house search was conducted to identify all cases and controls with help of cadre of health and village leader. A structured face-to-face interview, assisted with standard outbreak investigation questionnaire from the $\mathrm{MoH}$ of Indonesia, was conducted to all cases and controls. The questionnaire included various questions about demographic profiles, clinical information and contact to measles cases, measles immunization status, and travel history to district with documented measles outbreak. Immunization status for each case and control was determined through immunization record review. For those who had no immunization record or did not remember were categorized as unvaccinated group. A positive contact history with measles case was defined as those who had contact to a confirmed measles case. A positive travel history defined as those who had travel history to district with documented measles 7-23 days before fever and rash onset.

\subsection{Laboratory investigation}

Blood samples from ten suspected measles patients, selected randomly, were collected and transferred to the National Institute of
Health Research and Development of $\mathrm{MoH}$ for diagnostic testing. Detection of measles-specific IgM antibodies was conducted using Enzygnost Rubella ELISA kit following the manufacturer's protocol (Siemens Healthcare GmbH, Henkestr. Erlangen, Germany).

\subsection{Data and statistical analysis}

To evaluate the outbreak, age- and gender-specific attack rate (AR) of the outbreak was calculated. AR was calculated as the number of people who became ill divided by the number of population at risk for the infection. Case fatality rate (CFR) was calculated as the number of deaths associated with infection divided by the total number of cases and was expressed as a percentage (\%). Independent $t$-test was used to determine whether there were any difference between case and control group.

A two-step logistic regression was employed to assess the risk factors associated with measles infection. In the first step, all variables were analyzed in an unadjusted analysis. In the second step, variables with $p<0.25$ at univariate level were entered into the multivariable model. The estimated crude odds ratio (OR) of the univariate analyses and the adjusted OR (aOR) of the multivariate analyses were calculated together with $95 \%$ confidence interval (CI). The crude OR and aOR were compared to assess possible confounding. Significance was assessed at alpha 0.05 .

\subsection{Ethics approval and concern to participate}

This investigation was part of an emergency response to an outbreak and therefore no ethics approval was required. However, verbal concerns were provided from the parents/guardians prior to participation in the study.

\section{Results}

\subsection{Outbreak confirmation}

In Indonesia, a measles outbreak is declared when there are five or more clinical cases within four consecutive weeks, occur in cluster and epidemiologically linked to confirmed cases. ${ }^{21}$ Among ten blood samples, selected randomly from measles suspected cases, all were positive for measles-specific IgM antibodies and therefore the measles outbreak was confirmed. The investigation revealed that the first measles case was reported on 20 July 2015 . The index case was a 6 years old female child, who might get infected when travelling early of July to Serdang Bedagai District of North Sumatera in which measles outbreak also occurred from early of June to late of July $2015 .{ }^{10}$ The outbreak occurred more than five weeks, peaked on 19 August 2015 and the last case identified on 25 August 2015 (Fig. 1).

\subsection{Demographic and clinical characteristics}

There were 28 suspected measles cases identified during the outbreak. All cases presented with fever and maculopapular rashes. Other common symptoms were cough (80\%), coryza (65\%), and conjunctivitis (25\%). Age ranged from 1 year to 14 years (median 5 years) and $64.3 \%$ were male (Table 1 ).

\subsection{Outbreak characteristics}

The AR of the measles outbreak among population aged 0-14 years was $14.1 \%$ (28/198). The highest AR occurred among those aged 1-4 years old $(50.0 \%)$ followed by 5-9 years old (17.6\%) and 10-14 years old age group (3.1\%). The AR was higher among male than female with $24.3 \%$ and $8.1 \%$, respectively. There was no death occurred and therefore CFR was $0 \%$ (Table 1 ). 




Fig. 1. Number of measles cases by date of fever onset in Tanjung Pura Subdistrict, Langkat District, North Sumatera, Indonesia, 15 August - 25 September 2015 $(\mathrm{n}=28)$.

Table 1

Number of cases and attack rates of measles outbreak in Tanjung Pura Subdistrict, Langkat District, North Sumatera, Indonesia $(n=28)$.

\begin{tabular}{clllll}
\hline Variables & $\begin{array}{l}\text { Population at } \\
\text { risk }\end{array}$ & $\begin{array}{l}\text { Number of } \\
\text { cases }\end{array}$ & $\begin{array}{l}\text { Attack } \\
\text { rate (\%) }\end{array}$ & $\begin{array}{l}\text { Number of } \\
\text { death }\end{array}$ & $\begin{array}{l}\text { Case } \\
\text { fatality rate } \\
(\%)\end{array}$ \\
\hline \multicolumn{2}{c}{ Age group (year) } & & & & \\
$<1$ & 7 & 0 & 0.0 & 0 & 0.0 \\
$1-4$ & 26 & 13 & 50.0 & 0 & 0.0 \\
$5-9$ & 68 & 12 & 17.6 & 0 & 0.0 \\
$10-14$ & 97 & 3 & 3.1 & 0 & 0.0 \\
Gender & & & & & 0.0 \\
Male & 74 & 18 & 24.3 & 0 & 0.0 \\
Female & 124 & 10 & 8.1 & 0 & 0.0 \\
\hline
\end{tabular}

\subsection{Risk factors associated with measles infection}

There were 28 cases and 28 controls included in the case-control study and there was no different of demographic characteristics between case and control group (Table 2). The multivariate analysis found that being unvaccinated (aOR: 2.31, 95\% CI: 1.22-4.27) and contact with a measles case (aOR: 1.15, 95\% CI: 1.12-3.70) were significantly associated with measles infection (Table 3). Travel history to district with documented measles outbreak had no association with measles infection.

\section{Discussion}

Our epidemiological investigation confirmed a measles outbreak in Tanjung Pura Subdistrict, Langkat District, North Sumatera using criteria from $\mathrm{MoH}$ of Indonesia. ${ }^{21}$ The outbreak occurred from 20 July to 25 August 2015 and the AR up to 50\% among children aged 1-4 years
Table 2

Characteristics of cases $(n=28)$ and controls $(n=28)$ of measles outbreak in Tanjung Pura Subdistrict, Langkat District, North Sumatera, Indonesia.

\begin{tabular}{llll}
\hline Characteristic & Number of case (\%) & Number of control (\%) & p value \\
\hline Age group (year) & & & 0.08 \\
$1-4$ & $13(46.4)$ & $13(46.4)$ & \\
$5-9$ & $12(42.9)$ & $12(42.9)$ & \\
$10-14$ & $3(10.7)$ & $3(10.7)$ & 0.72 \\
Gender & & & \\
$\quad$ Male & $18(64.3)$ & $18(64.3)$ & 0.92 \\
$\quad$ Female & $10(35.7)$ & $10(35.7)$ & \\
Parents' level of education & & \\
$\quad$ Primary & $2(7.1)$ & $3(10.7)$ & \\
Secondary & $20(71.4)$ & $17(60.7)$ & \\
Tertiary & $6(21.5)$ & $8(28.6)$ & \\
Parents' occupation & & & \\
Businessman & $4(14.3)$ & $3(10.7)$ & \\
Employee & $6(21.4)$ & $9(32.1)$ & \\
Farmer & $15(53.6)$ & $14(50.0)$ & \\
Housewife & $3(10.7)$ & $2(7.2)$ &
\end{tabular}

Table 3

Factors associated with measles outbreak in Tanjung Pura Subdistrict, Langkat District, North Sumatera, Indonesia.

\begin{tabular}{lllll}
\hline Variables & Crude OR & 95\% CI & Adjusted OR & 95\% CI \\
\hline Non vaccination & 2.76 & $1.19-7.56$ & 2.31 & $1.22-4.27$ \\
Contact with a measles case & 1.43 & $1.01-5.86$ & 1.15 & $1.12-3.70$ \\
$\begin{array}{c}\text { Travel history to district with } \\
\quad \text { measles outbreak }\end{array}$ & 0.67 & $0.11-3.99$ & 0.52 & $0.02-2.87$ \\
\hline
\end{tabular}


old. Being unvaccinated and having a contact history with measles cases were two main risk factors of the outbreak. This finding is inline with other studies that revealed that measles cases related to non-vaccination status. ${ }^{5,6,22-26}$

Measles vaccination increases the immunity against measles ${ }^{1-4}$ and high vaccination coverage reduces the risk of measles infection in the community. ${ }^{24,27,28}$ Provision of measles vaccine is included in the Complete Routine Immunization Program recommended by the $\mathrm{MoH}$ of Indonesia. ${ }^{16-18}$ Unfortunately, Indonesia is one of the top 10 countries with the most unvaccinated children. ${ }^{19}$ In the last ten years, measles immunization coverage in North Sumatra never reach 95\% and in 2018 measles-rubella vaccination coverage was $59.8 \%$ only. ${ }^{29}$ Many misconceptions about measles vaccine have persisted because of a poor understanding the vaccine itself. One of misconception about measles vaccination is that the vaccine can cause autism in children. In some areas, the refusal of vaccination due to the view that the vaccine contained pork gelatin, which is forbidden in religion. ${ }^{19,30}$

In Indonesia, low vaccination coverage is also observed for diphtheria-tetanus-pertussis (DTP3) vaccination where DTP3 vaccination coverage has declined below $80 \%$ in the country since $2014 .{ }^{31}$ In 2017 , not surprisingly, diphtheria outbreak occurred in all main islands in Indonesian archipelago where the highest incidence rate was reported in a province with the lowest DPT vaccination coverage. ${ }^{31}$ One of the main reason is vaccine hesitancy among community members in Indonesia. A previous study found that approximately $33 \%$ out of 1,059 community members in Indonesia had poor view regarding vaccines. ${ }^{32}$ In addition, $61.6 \%$ out of 956 parents in Indonesia showed hesitancy towards childhood vaccination in term of safety and efficacy issue. ${ }^{33}$ Altogether these indicate that vaccine hesitancy is still the main issue in the country.

Our investigation also found that contact history with measles cases was another risk factor for the outbreak. Contact history refers to sharing the same air space, usually an enclosed area (for example living in the same household or being in the same room, school, health facility waiting room, office or transport) for any length of time with a case during the case's infectious period. ${ }^{1,2,26}$ In addition, the virus remains contagious in the air or on infected surfaces for up to $2 \mathrm{~h}$ even if the contact was not in the same room at the exact same time as the case. ${ }^{1}$ This is due to the nature of this disease transmission by respiratory droplets or airborne spray. ${ }^{4-6,24}$ Our study revealed that the cases had contact history with another confirmed case at home, school, or other public spaces. This finding is consistent with other studies where individuals who had a contact history with measles cases had a higher risk of acquiring infection compared to those had no contact during outbreak. ${ }^{10,26,34}$

\subsection{Public health action recommendations}

During the outbreak, intensive information, education and communication (IEC) campaigns were conducted to eliminate the misconceptions of measles vaccination. A mass measles immunization to the school children was conducted to the affected area and all cases were provided with a supportive treatment with vitamin A to reduce complications. In addition, we recommended all community health centers and authorities to conduct a strict measles surveillance and notification system and effected area must notify border districts' authorities to control the measles transmission in the future.

\section{Conclusions}

An outbreak of measles was confirmed in Tanjung Pura Subdistrict, Langkat District, North Sumatera. Being unvaccinated and having a contact history with a measles case were the most potential risk factors associated with the outbreak.

\section{Funding}

None.

\section{Conflicts of interest}

None.

\section{Acknowledgements}

The authors would like to acknowledge to the surveillance staffs in District Health Office of Langkat and Puskesmas Tanjung Pura for providing assistance in conducting the investigation as well as Head of National Institute of Health Research and Development, Ministry of Health of Indonesia for valuable advice.

\section{Appendix A. Supplementary data}

Supplementary data to this article can be found online at https:// doi.org/10.1016/j.cegh.2019.08.006.

\section{References}

1. World Health Organization. Measles. Vaccine-preventable diseases surveillance standards. 2018; 2018:1-29.

2. Gastanaduy PA, Redd SB, Clemmons NS, et al. Chapter 7: Measles. VPD Surveillance Manual. Centers for Disease Control and Prevention; 2000https://www.cdc.gov/ vaccines/pubs/surv-manual/chpt07-measles.pdf.

3. Fiebelkorn AP, Seward JF, Orenstein W, Diseases R. A global perspective of vaccination of healthcare personnel against measles: systematic review. Vaccine. 2015;32(38):4823-4839..

4. Griffin DE. Measles vaccine. Viral Immunol. 2018;31(2):86-95. https://doi.org/10. 1089/vim.2017.0143.

5. Lekana-douki SE, Sir-ondo-enguier PN, Banga-mve-ella O. Epidemiology and molecular characterization of the re-emerging measles virus among children and adults in the Haut-Ogooue, Gabon. BMC Infect Dis. 2019;19(90):1-8.

6. Dabbagh A, Patel MK, Dumolard L, et al. Progress toward regional measles elimination - worldwide, 2000 - 2016. Morb Mortal Wkly Rep. 2017;66(42):1148-1153.

7. Perry RT, Halsey NA. The clinical significance of measles: a review. J Infect Dis. 2004;189(Suppl 1):S4-S16.

8. Tobin M. Measles cases spike in Indonesia, Malaysia and Philippines as anti-vaxxers take to social media. This Week in Asia; 2019https://www.scmp.com/week-asia/healthenvironment/article/3003734/measles-vaccine-preventable-diseases-rise-southeast, Accessed date: 10 June 2019.

9. World Health Organization. Measles Rubella Immunization Campaign in Java Island on Aug-Sep 2017. WHO SEARO; 2017http://www.searo.who.int/indonesia/topics/ immunization/MR_CAMPAIGN/en/, Accessed date: 10 June 2019.

10. Sitepu FY. A measles outbreak in Serdang Bedagai district, Indonesia. Int J Epidemiol. 2015;44(suppl 1) i123.

11. Hartoyo E, Wiyatno A, Anton U, et al. Occurrence of measles genotype D8 during a 2014 outbreak in Banjarmasin, South Kalimantan, Indonesia. Int J Infect Dis. 2017:;54:1-3.

12. Sulistyawati S, Sumiana S. Measles cluster detection using ordinal scan statistic model. Mater Sociomed. 2018;30(4):282-286.

13. Mukhibin A, Ahmad RA, Kusnanto H. Economic burden analysis of measles outbreak in Yogyakarta, 2015. Ber Kedokt Masy. 2015;32(12):473-480.

14. Ningtyas DW, Wibowo A. The influence of measles vaccine quality to the incidence of measles, Pasuruan district, East Java, Indonesia, 2015. J Berk Epidemiol. 2015;3(3):315-326.

15. Oktaviasari KE. Being unvaccinated and the incidence of measles, East Java, Indonesia. J Berk Epidemiol. 2018;6(2):166-173.

16. Ministry of Health Republic of Indonesia. Indonesia Health Profile; 20172018.

17. World Health Organization. Indonesia EPI Fact Sheet. 2016; 2016.

18. Ministry of Health Republic of Indonesia. Technical guidelines for measles and rubella immunization campaigns. 2017; 2017

19. Coe M, Gergen J, Phily C, Ozaltin A. "Indonesia Country Brief". Sustainable Immunization Financing in Asia Pacific. 2017; 2017 Washington, DC.

20. Langkat Health Office. Langkat Health Profile Report. 2016; 2016.

21. Ministry of Health Republic of Indonesia. Indonesia Health Profile; 20152016.

22. Billard M-N, Serres G De, Gariepy M-C, et al. Prevalence of risk factors for acquiring measles during the 2011 outbreak in Quebec and impact of the province-wide schoolbased vaccination campaign on population immunity. PLoS One. 2017;12(10).

23. Banerjee E, Debolt C, Bravo-alc P, et al. Public health responses during measles outbreaks in elimination settings: strategies and challenges. Hum Vaccines Immunother. 2018;14(9):2222-2238.

24. Zheng X, Zhang N, Zhang X, Hao L, Su Q, Wang H. Investigation of a measles outbreak in China to identify gaps in vaccination coverage, routes of transmission, and interventions. PLoS One. 2015;10(7):e0133983.

25. Hagan JE, Takashima Y, Sarankhuu A, et al. Risk factors for measles virus infection 
among adults during a large outbreak in postelimination era in Mongolia, 2015. $J$ Infect Dis. 2017;216(15 November):1187-1195.

26. Vemula VN, Li L, Thoon KC, et al. Risk factors and clinical profile of measles infection in children in Singapore. Infect Dis Heal. 2016;21(4):192-196.

27. Strebel PM, Cochi SL, Hoekstra E, et al. A world without measles. J Infect Dis. 2011;204(July):2011-2014

28. Afzal S, Afzal BB. Risk factors associated with the outbreak of measles in Lahore, Pakistan. Annals. 2014;20(4):302-309.

29. Provincial Health Office of North Sumatera. Report of catch-up campaign measles-rubella vaccination coverage. 2019; 2019.

30. Sawitri AS. Indonesia, India fall behind in measles vaccination. The Jakarta Post; 2017 Published https://www.thejakartapost.com/news/2017/09/06/indonesia-india-fall- behind-in-measles-vaccination.html.

31. WHO SEARO. South-East Asia regional vaccine action plan 2016-2020. SEARO Publication; 2017.

32. Harapan H, Alleta A, Anwar S, Setiawan AM. Letter to the editor socio- demographic factors associated with inhabitants' view related to vaccines in Indonesia. Iran $J$ Public Health (English ed). 2017;46(5):708-710

33. Yufika A, Wagner A, Nawawi Y, et al. Parents' hesitancy towards vaccination in Indonesia: The results from the Indonesia Zika Vaccine Study (Unpubl data).

34. Girmay A, Dadi AF. Being unvaccinated and having a contact history increased the risk of measles infection during an outbreak: a finding from measles outbreak investigation in rural district of Ethiopia. BMC Infect Dis. 2019;8:345. 